\title{
Fibrosis quística, diagnóstico desde Atención Primaria
}

\author{
MS. Martínez García, ML. Casado Sánchez \\ Pediatra. CS San Blas. Parla, Madrid. España.
}

\begin{abstract}
Resumen
La fibrosis quística es una enfermedad autosómica recesiva, causada por mutaciones en el gen de la proteína reguladora de la conductancia transmembrana, en el brazo largo del cromosoma 7. Es característica la variabilidad clínica, con obstrucción e infección en las vías respiratorias, maldigestión y retraso del desarrollo, siendo diagnóstico diferencial de muchos trastornos pediátricos. La afectación pulmonar determina su morbimortalidad. Presenta multitud de mutaciones genéticas, en continua identificación, que determinan los fenotipos. El diagnóstico no es fácil, pues los criterios clínicos y de laboratorio existentes se redefinen conforme avanza la investigación. Gracias a sospechas diagnósticas precoces y a la implantación del cribado neonatal, que permiten un tratamiento precoz, la enfermedad presenta mejor pronóstico y supervivencia.

Es relevante incidir en que el diagnóstico desde Atención Primaria es posible, si se conoce la enfermedad, se sospecha, y se realiza el cribado neonatal.

Presentamos dos casos de diagnóstico desde Atención Primaria, uno con manifestaciones respiratorias y otro, digestivas.
\end{abstract}

Palabras clave: Fibrosis quística. Atención Primaria. Diagnóstico.

\section{Cystic fibrosis, a diagnosis at Primary Care}

\section{Abstract}

Cystic fibrosis (CF) is an autosomal recessive disease caused by mutations in the gene encoding the CF transmembrane conductance regulator. It is characterized by numerous clinical variations: airway obstruction and infection, maldigestion, delay of the development... The lung injury determines morbidity and mortality. CF has a great deal of genetic mutations, which produce different phenotypes. However, the diagnosis is not easy and criteria are constantly revised after the latest scientific research. Since we can suspect the illness before than some years ago and due to the neonatal screening and the early treatments, prognosis and survival have improved in comparison with the last century.

It is worth insisting on the fact that diagnosis at Primary Care is possible: knowing the illness, suspecting it and carrying out the neonatal screening.

We present two cases at a Primary Care Unit, one of them manifesting respiratory symptoms and the other one digestive ones.

Key words: Cystic fibrosis. Primary Health care. Diagnosis.

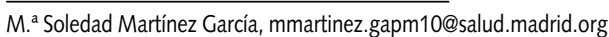

Los autores declaran no presentar conflictos de intereses en relación con la preparación y publicación de este artículo. 


\section{Introducción}

La fibrosis quística (FQ) es una enfermedad multisistémica autosómica recesiva con disfunción de las glándulas exocrinas y caracterizada por infección y obstrucción crónica de las vías respiratorias e insuficiencia pancreática ${ }^{1}$. La incidencia en caucásicos oscila entre 1:900 (Québec) y 1:5352 (Cataluña) recién nacidos vivos, 1:2000 en judíos mediterráneos, 1:31 000 en asiáticos y 1:17 000 en afroamericanos ${ }^{2,3}$. Existe un portador por cada 20-25 sanos en población blanca.

La proteína que se altera (de $1480 \mathrm{ami}$ noácidos), codificada por un gen del brazo largo del cromosoma 7 (7q31.2), es la reguladora de la conductancia transmembrana de la FQ (CFTR) y funciona como canal iónico de cloro. Su inactividad provoca alteraciones hidroelectrolíticas en las secreciones de las vías digestiva y respiratoria, las glándulas sudoríparas, el aparato genitourinario, etc., lo que da lugar a infecciones crónicas 4 .

Un diagnóstico precoz y un tratamiento adecuado mejoran la supervivencia y la calidad de vida (en los años 40, la supervivencia media era de dos años, mientras que actualmente supera los 30 años) $)^{5}$. De ahí el interés del diagnóstico desde Atención Primaria (AP), donde estos pacientes consultan por primera vez.

\section{Caso clínico 1}

(con debut respiratorio)

Varón de dos años y 11 meses de edad, que comenzó la asistencia a guardería a los ocho meses, con cuadros respiratorios continuos, entre los cuales los más relevantes fueron:

A los 14 meses: fiebre, tos espástica e irritativa, mocos y auscultación normal que respondió a tratamiento con broncodilatadores.

A los 16 meses: roncus diseminados y espiración alargada que también respondió a tratamiento con broncodilatadores.

A los 19 meses: fiebre, malestar general y dificultad respiratoria con roncus, sibilancias espiratorias y estertores en base pulmonar izquierda. Se realizó una radiografía torácica que objetivó infiltrados pulmonares en la língula, con atelectasia en el lóbulo medio. Precisó broncodilatador y antibioterapia. Empeoró y precisó ingreso al día siguiente, con diagnóstico de neumonía bilobar de los lóbulos medio derecho e inferior izquierdo y atelectasia del lóbulo superior derecho con antígeno de neumococo positivo en orina.

Se solicitó ionotest ante los cuadros respiratorios de repetición. Los resultados a los 21 meses (bronquitis tratada con salbutamol y antibioterapia ambu- 
latoria) fueron un ionotest con cloro $(\mathrm{Cl})$ de $70 \mathrm{mmol} / \mathrm{l} ;$ y a los 22 meses (neumonía en língula y atelectasias) fue un ionotest con $\mathrm{Cl}$ de $83 \mathrm{mmol} / \mathrm{l}$, y amilasa, lipasa y grasa en heces normales.

La confirmación genética se obtuvo a los 27 meses: $\triangle \mathrm{F} 508$ y L206W.

A raíz de estos procesos, dejó la guardería a los 24 meses. Solo tuvo un episodio posterior similar, con moco nasal positivo para virus de la gripe $A$ que se trató ambulatoriamente con oseltamivir. Actualmente permanece asintomático.

\section{Caso clínico 2}

(con debut gastrointestinal)

Varón de dos años y tres meses de edad que debutó con fallo de medro al mes de vida, con ingesta adecuada para la edad y el peso. En ese momento, se objetivó edema de párpados superiores, palidez cutánea, leve distrofia muscular en muslos y glúteos, e hipotonía de miembros superiores y cervicoaxial. Se realizaron urocultivo (negativo) y controles de tomas y peso, con glucemia capilar de $78 \mathrm{mg} / \mathrm{dl}$. Durante uno de esos controles, en la consulta, realizó una deposición bien conformada, verdosa y brillante, por lo que se solicitó estudio de heces (negativo para hemoglobina, buena digestión de hidratos de carbono y fibras musculares, se observaban grasas). Se pautó hidrolizado de leche de vaca, a raíz de lo cual empezó a estar más activo, con mejor tono muscular y ganancia ponderal.

Se solicitaron dos ionotest, que resultaron de $105 \mathrm{mmol} / \mathrm{l}$ y $100 \mathrm{mmol} / \mathrm{l}$ de $\mathrm{Cl}$. A los tres meses, se inició tratamiento con pancreatina $y$, a los cuatro meses, con vitaminas $A, D, E$ y K. El estudio genético mostró como resultado la alteración $\Delta$ F508del/G542X.

A los ocho meses, se realizó un cultivo de moco nasal, que resultó positivo para Pseudomonas aeruginosa sin síntomas respiratorios, y fue tratado con ciprofloxacino oral.

A los 14 meses, en una ecografía abdominal se visualizó barro en la vesícula biliar y se pautó tratamiento con ácido ursodeoxicólico y normalización de su alimentación (leche no hidrolizada).

Actualmente, precisa tratamiento con vitaminas liposolubles, pancreatina, ácido ursodeoxicólico, palivizumab mensual y dornasa alfa. El niño no presenta alteraciones psicomotoras y mantiene buena ganancia ponderoestatural.

\section{Discusión}

Para la realización de las pruebas de confirmación diagnóstica pertinentes, los pacientes deben ser derivados a unidades 
hospitalarias; no obstante, es posible realizar una aproximación diagnóstica de FQ desde AP, teniendo en cuenta que los criterios diagnósticos aceptados son ${ }^{4,6,7}$ :

- Clínicos, uno o más entre: fenotipo (enfermedad respiratoria o digestiva compatible, ausencia de conductos deferentes o síndromes pierde-sal), historia familiar y cribado neonatal positivo.

- Disfunción de CFTR: Cl en sudor $>60 \mathrm{mmol} / \mathrm{l}$ en dos ocasiones; presencia de dos mutaciones; alteración de la diferencia de potencial nasal.

El test del sudor confirma el diagnóstico determinando la concentración de cloro en sudor (> $60 \mathrm{mmol} / \mathrm{l}$ según Gibson y Cooke $\left.{ }^{8}\right)$. Si el resultado es dudoso o normal, se puede realizar la diferencia de potencial nasal transepitelial.

Los criterios clínicos digestivos o respiratorios son los que dieron la pista en los pacientes presentados, dado que no tenían realizado el cribado neonatal para FQ. Desde AP se inició el estudio diagnóstico para el tratamiento precoz de ambos.

Actualmente, se dispone del cribado neonatal en algunas comunidades autónomas, aunque no todas lo realizan, por lo que los datos clínicos siempre deben incluir la FQ en el diagnóstico diferencial.

- Cribado neonatal: los criterios para cualquier cribado son alta sensibilidad y especificidad, enfermedad grave, tratamiento eficaz, bien aceptado por la población, que mejore las expectativas de los enfermos y que sea asumible económicamente. En la FQ se cumplen estos requisitos con la tripsina inmunorreactiva (TIR).

En España se ha aplicado en más de un millón de recién nacidos, y han sido diagnosticados más de 200. En diez años, en Cataluña se han estudiado 712597 recién nacidos, con una incidencia de 1:5840; en CastiIla y León, de 1:4339; en Galicia, de 1:4430; en Murcia, de 1:5376, y en Baleares, de 1:6602. Aragón y Extremadura también realizan el cribado neonatal'.

En Castilla y León se implantó en 2001 y aproximadamente diez de cada 1000 recién nacidos presentan TIR alta y precisan estudio genético. Tras realizarlo, se estiman 0,23:1000 afectos y 0,58:1000 portadores. De ello se deduce que más del $90 \%$ de las TIR elevadas son falsos positivos, pero elevar la 
cifra de corte o repetir la prueba supondría incrementar los falsos negativos ${ }^{5}$.

El Programa de Cribado Neonatal de Metabolopatías Universal, dentro del Programa de Salud Pública, lo ha incorporado desde julio de 2009 en la Comunidad de Madrid, aunque todavía se están esperando las primeras estadísticas. Si el resultado del cribado es dudoso, se busca la confirmación genética, como en Castilla y León, con consentimiento informado. Dicho consentimiento se otorga de forma escrita por los padres en el momento de realización de la prueba, desde enero de 2011 en la Comunidad de Madrid $^{10}$.

\section{Conclusiones}

La FQ es una enfermedad muy incapacitante en su evolución, tanto a nivel pulmonar como digestivo, con medidas preventivas muy eficaces si se conoce.

El diagnóstico temprano mejora la calidad y la esperanza de vida. Por consiguiente, el cribado neonatal es de vital importancia.

No está implantado en toda España, por lo que la patología debe seguir teniéndose en cuenta en el diagnóstico diferencial de las patologías respiratorias y digestivas infantiles.

Como demuestra este artículo, desde AP es posible y deseable el diagnóstico de $F Q$, pues ofrece un tiempo precioso para el tratamiento precoz de las patologías asociadas y sus complicaciones.

\section{Bibliografía}

1. Welsh MJ, Tsui LC, Boat TF, Beaudet AL. Cystic fibrosis. En: Scriver CR, Blaudet AL, Sly WS (eds.). The metabolic and molecular bases of inherited disease. New York: McGraw Hill; 1995. p. 3799-876.

2. Boat TF. Fibrosis quística. En: Behrman $E$, Kliegman RM, Jenson HB (eds.). Nelson Tratado de Pediatría, 17. ${ }^{a}$ ed. Madrid: Elsevier; 2004. p. 1437-50.

3. Molina M, Ramos E. Fibrosis quística. Aspectos digestivos y nutricionales. An Pediatr Contin. 2008;6(2):65-75.
4. Gutiérrez V, Olivera MJ, Girón RM, Rodríguez-Salvanés $F$, Caballero P. Fibrosis quística en adultos: acuerdos inter e intraobservador para las escalas de puntuación de Brasfield y Chrispin-Norman en la radiografía de tórax y relación con datos clínicos y espirométricos. Arch Bronconeumol. 2005;41:553-9.

5. Tellería JJ, Alonso MJ, Blanco A. Cribado neonatal de la fibrosis quística. An Pediatr Contin. 2005;3(3):168-72.

6. Máiz L, Baranda F, Coll R, Prados C, Vendrell $M$, Escribano $A, y$ cols. Normativa del diagnóstico y el tratamiento de la afección respiratoria en la fibrosis quística. Arch Bronconeumol. 2001;37:316-24. 
7. Barrio $\mathrm{MI}$, Antelo C. Fibrosis quística. Enfermedad respiratoria. An Pediatr Contin. 2008;6(2): 59-64.

8. Lewis F, Gibson MD, Robert E, Cooke MD. A test for concentration of electrolytes in sweat in cystic fibrosis of the pancreas utilizing pilocarpine by iontophoresis. Pediatrics. 1959;23:545-9.

9. Gartner S, Cobos N. Cribado neonatal para la fibrosis quística. An Pediatr (Barc). 2009;71:481-2.
10. Art. 5 de la Orden $237 / 2010$ de 5 de mayo de 2010, Boletín Oficial de la Comunidad de Madrid, núm. 124, por la que se dictan normas en relación a las pruebas de cribado para la detección precoz de enfermedades y prevención de minusvalías en recién nacidos [consultado el 25/01/2011]. Disponible en www.madrid.org/cs/Satellite? language $=$ es\&pagename $=$ Boletin $\% 2 \mathrm{FPage} \% 2 \mathrm{FB}$ OCM_home 